\title{
CARACTERIZAÇÃO AGRONÔMICA DE UMA LAVOURA DE CAFÉ CONILON DA VARIEDADE CLONAL VITÓRIA INCAPER 8142
}

\author{
Eduardo Sudre Pereira ${ }^{1}$ \\ Richardson Sales Rocha ${ }^{2}$ \\ Sandy Queiroz Espinoso ${ }^{3}$ \\ Matheus Wandermurem da Silva ${ }^{4}$ \\ Mykael Corrêa Alves ${ }^{5}$ \\ luri Targa Nunes Galvão ${ }^{6}$ \\ Ismael Lourenço de Jesus Freitas ${ }^{7}$ \\ Jéferson Luiz Ferrari ${ }^{8}$
}

Resumo: O objetivo desse trabalho foi avaliar as características agronômicas de uma lavoura da variedade clonal Vitória Incaper 8142. Foram avaliados as alturas das plantas, número de hastes e os diâmetros de caules dos treze clones da variedade clonal. Foi realizado também, o georreferenciamento das plantas avaliadas visando à elaboração do croqui do experimento. Em média, a altura das plantas foi de 1, $86 \mathrm{~m}$, com diâmetro médio de caule de $2,63 \mathrm{~cm}$, considerando 3,26 como sendo o número médio de hastes por planta. O clone que apresentou maior altura foi o clone $8 \mathrm{com} 2,8 \mathrm{~cm}$ e o que apresentou menor altura foi

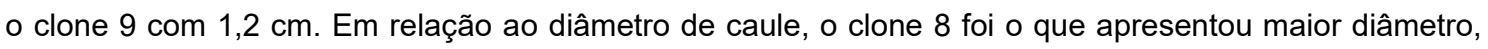
com 4,3 cm em um dos caules. Os clones 4 e 5, foram os que apresentaram menor diâmetro em um dos caules, com $1,4 \mathrm{~cm}$.

Palavras-chave: Melhoramento genético; Coffea canéfora; Geotecnologia.

\footnotetext{
1 Cafeicultura/IFES, Brasil, E-mail: eduardo-sudre@hotmail.com.

2 Cafeicultura/IFES, Brasil, E-mail: richardsonsales2016@gmail.com.

3 Cafeicultura/IFES, Brasil, E-mail: sandyespinoso@gmail.com.

${ }^{4}$ Cafeicultura/IFES, Brasil, E-mail: matheus-wandermurem@hotmail.com.

${ }^{5}$ Cafeicultura/IFES, Brasil, E-mail: mykael.correa@hotmail.com.

${ }^{6}$ Cafeicultura/IFES, Brasil, E-mail: iuritngalvao@gmail.com.

7 Cafeicultura/IFES, Brasil, E-mail: ismaelljf@yahoo.com.br.

${ }^{8}$ Cafeicultura/IFES, Brasil, E-mail: ferrariluiz@gmail.com.
} 